\title{
Studies on prostaglandin metabolism in corpora lutea of rabbits during pregnancy and pseudopregnancy
}

\author{
W. Schlegel, S. Krüger, D. Daniels, B. Fischer*, H. P. G. Schneider and \\ H. M. Beier*
}

Frauenklinik der Westfälischen Wilhelms-Universität, Albert-Schweitzer-Str. 33, D-4400 Münster, Federal Republic of Germany; and * Abteilung Anatomie und Reproduktionsbiologie, Medizinische Fakultät, RWTH Aachen, Melatener Str. 211, D-5100 Aachen, Federal Republic of Germany

\begin{abstract}
Summary. Corpora lutea and ovarian stromal tissue were anlaysed for prostaglandin (PG) concentrations and activities of enzymes involved in PG metabolism at 8, 10, 12, 13 and 15 days after induction of ovulation. In CL of pseudopregnant rabbits, the PGE-2-9-ketoreductase (PGE-2-9-KR) was highly active on Days 10, 12 and 15 when compared with Day $8(P<0.01 ; P<0.001 ; P<0.05)$. In pregnant animals PGE-2-9KR activity was only increased on Day $12(P<0.05)$ but declined to basal levels on Days 13 and 15. Comparing PGE-2-9-KR activity of pseudopregnant and pregnant animals, a significant elevation was found on Day 15 of pseudopregnancy $(P<0.025)$. Activities of PG-15-hydroxydehydrogenase did not exhibit any significant changes with time in pseudopregnant or pregnant rabbits.

PGE-2 concentrations were increased on Days 12,13 and $15(P<0.025)$ when compared with Day 8 . Changes in PGF- $2 \alpha$ concentrations paralleled those of PGE-2 9-KR. The concentrations of PG metabolites 13,14-dihydro-15-keto-PGE-2 and -PGF-2 $\alpha$ were lower than those of the primary PGs and did not show stage-specific changes in pseudopregnant and pregnant animals.

These results demonstrate that the rabbit CL posesses enzymes to convert PGE-2 to PGF- $2 \alpha$ and to metabolize both PGs. PGE-2-9-KR may be involved in regulating the PGF-2 $\alpha /$ PGE-2 ratio and possibly in controlling the life-span of the corpus luteum.
\end{abstract}

Keywords: PGE-2-9-ketoreductase; prostaglandin-15-hydroxydehydrogenase; luteolysis; prostaglandin metabolism; pseudopregnancy; rabbit

\section{Introduction}

Corpus luteum function in pseudopregnant rabbits lasts from Day 1 to Day 12 after hCG as demonstrated by peripheral progesterone concentrations. Progesterone concentrations decline at about Day 12, indicating luteal regression (for references see Harrington \& Rothermel, 1977; Fischer et al., 1985, 1986; Busch et al., 1986). In contrast, corpora lutea of pregnant animals remain intact until the onset of parturition.

There is evidence in many species that prostaglandin (PG) E-2 acts as a luteotrophic factor while PGF-2 $\alpha$ is involved in luteal regression (Horton \& Poyser, 1976). However, the biochemical events leading to functional and structural luteolysis have still to be clarified. PGF- $2 \alpha$ may act in changing the ovarian-luteal blood flow or in changing the LH receptor binding capacity (Pong \& Behrman, 1981). However, the regulation and site of production of this PG are still unknown.

In pigs, cows and sheep, PGF- $2 \alpha$ of uterine origin has been strongly implicated as the physiological luteolytic signal (Hansel et al., 1973) and Flint \& Sheldrick (1986) have described a positive feedback loop between luteal and uterine tissues in sheep. According to this hypothesis the pulsatile secretion of PGF-2 $\alpha$ from the uterus seems to be responsible for luteolysis. In other species like the 
Arachidonic acid

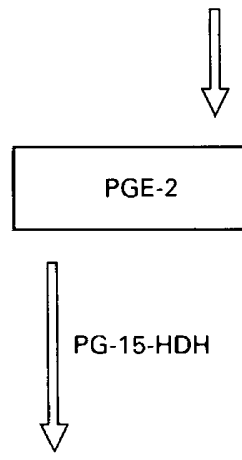

13,14-DHK PGE-2
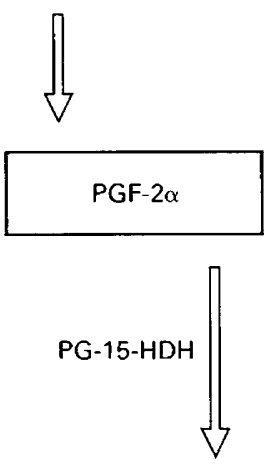

13,14-DHK PGF-2 $\alpha$

Fig. 1. Turnover and metabolism of PGE-2 and PGF-2 $\alpha$. Abbreviations: PGE-2 = prostaglandin E-2 (luteotrophic factor); PGF-2 $\alpha=$ prostaglandin F-2 $\alpha$ (luteolytic factor); 13,14DHK-PGE-2 = 13,14-dihydro-15-keto prostaglandin E-2; 13,14-DHK-PGF- $\alpha=13$, 14dihydro-15-keto prostaglandin F-2 $\alpha$; PGE-2-9-KR = prostaglandin E-2-9-ketoreductase; $\mathrm{PG}-15-\mathrm{HDH}=$ prostaglandin-15-hydroxydehydrogenase.

rabbit, exogenously applied PGF-2 $\alpha$ terminates corpus luteum function. PGF- $2 \alpha$ is suspected to be produced within the ovary and possibly in the corpus luteum itself and may act in a paracrine rather than an endocrine fashion. The intracellular location of PG biosynthesis and its metabolism (Fig. 1) may be organized as proposed by Schlegel et al. (1974), suggesting that the enzymes of PG biosynthesis and conversion (PGE-2-9-ketoreductase (PGE-2-9-KR) and prostaglandin 15hydroxydehydrogenase (PG-15-HDH)) determine the intracellular PGF-2 $\alpha /$ PGE-2 ratio and thereby the luteotrophic or luteolytic activity of the prostaglandins.

We have been able to isolate and to partly purify PGE-2-9-KR and PG-15-HDH from rabbit ovarian tissue (Schlegel et al., 1987) at the time of luteolysis. The suggestion that PGF-2 $\alpha$ might be synthesized in the rabbit corpus luteum itself and that intracellular PG concentrations might be regulated by the cited enzymes has been explored in the present study.

\section{Materials and Methods}

Animals. Sexually mature rabbits of mixed breed and 5 bucks of proven fertility were used. The 40 does were primed with a single injection of 100 i.u. PMSG (Seragon: Ferring, Kiel, FRG). After 3 days, 20 of the does were mated and ovulation was ensured by intravenous injection of 75 i.u. hCG (Prolan: Bayer, Leverkusen, FRG). Pseudopregnancy was induced by hCG alone 3 days after PMSG priming $(\mathrm{N}=20)$. The rabbits were killed by a rapid intravenous injection of $3 \mathrm{ml}$ embutramide, mebezonium iodide and tetracaine hydrochloride (T61, Hoechst, Unterschleißheim, FRG) on Days 8, 10, 12,13 or 15 of pregnancy or pseudopregnancy. Corpora lutea and ovarian stroma were separated and the endometrial mucosa was scraped from myometrium. All specimens were frozen in liquid nitrogen within 30 min after killing.

Sample preparation. The measurements were preceded by homogenization and centrifugation. The individual samples were washed several times with ice-cold $\mathrm{NaCl}(0.15 \mathrm{M})$, homogenized in a Potter-Elvehjem Homogenizer and centrifuged at $12000 \mathrm{~g}$ for $15 \mathrm{~min}$. Samples of the resulting supernatants for determinations of PGE-2, PGF-2 $\alpha$, 13,14-dihydro-15-keto-PGE-2 (DHKE-2) and 13,14-dihydro-15-keto-PGF-2 $\alpha$ (DHKF-2 $\alpha$ ) were acidified with 1-5 Mcitric acid and immediately extracted with ethyl acetate. Samples for enzyme activity measurements were dialysed against buffer containing $10 \mathrm{~mm}$-potassium phosphate, $\mathrm{pH} 7 \cdot 1,1 \mathrm{~mm}$-EDTA, $1 \mathrm{~mm}$-dithiothreitol, 20\% glycerol for $24 \mathrm{~h}$. All steps were carried out at $4^{\circ} \mathrm{C}$.

The total protein was determined by the method of Bradford (1976) using BSA as standard.

Enzyme activities. The activities of PGE-2-9-KR (EC 1.1.1.189) and PG-15-HDH (EC 1.1.1.141) were measured as described previously (Schlegel \& Greep, 1975; Krüger \& Schlegel, 1986). One unit of PGE-2-9-KR is defined as the amount of enzyme which catalyses the production of 1 pmol PGF- $2 \alpha /$ min and one unit of PG-15-HDH that which catalyses production of $1 \mu \mathrm{mol} \mathrm{NADH} / \mathrm{min}$ under standard assay conditions.

Radioimmunoassays. PGE-2, PGF-2 $\alpha$, DHKE-2 and DHKF-2 $\alpha$ were estimated by radioimmunoassay (Schlegel 
Table 1. Enzyme activities, prostaglandin and prostaglandin metabolite concentrations during pseudopregnancy and pregnancy in rabbits

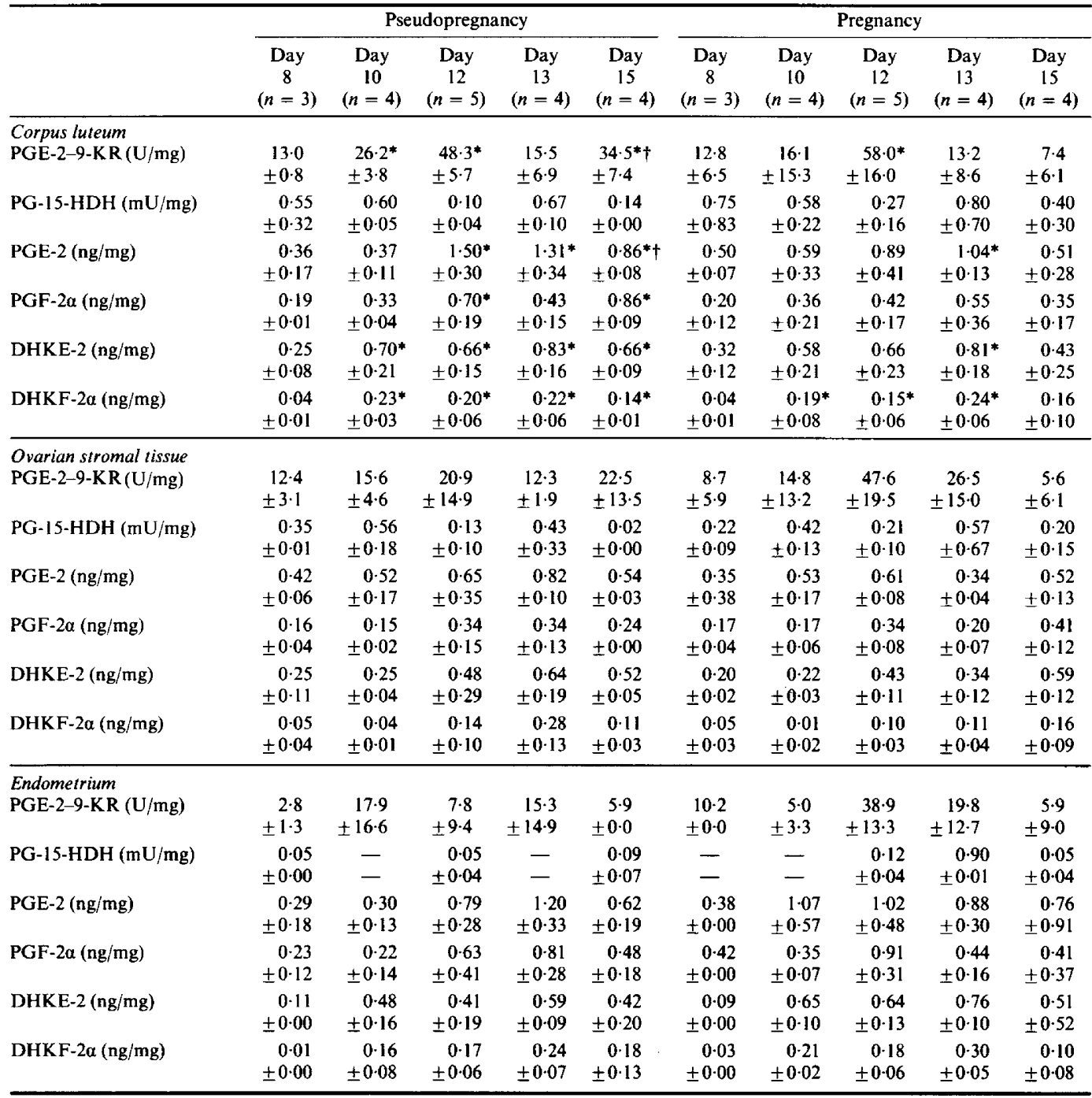

Values are means \pm s.d.

*Significantly increased $(P<0.05)$ compared with Day 8.

†Significantly increased $(P<0.05)$ compared with Day 15 of pregnancy.

et al., 1977, 1982, 1983, 1985). The sensitivities of the assays were $60 \mathrm{pg} / \mathrm{ml}$ for PGE-2 and PGF-2 $\alpha$ and 7.8 and $1.9 \mathrm{pg} / \mathrm{ml}$ for DHKE-2 and DHKF-2 $\alpha$, respectively. The cross-reactivity of antiserum to PGE- 2 was $<0 \cdot 1 \%$ for PGF-2 $\alpha$, PGI-2, PGD-2 and other prostaglandins except for PGA-2 $(70 \%)$ and PGE-1 $(50 \%)$. The antibodies to PGF-2 $\alpha$, DHKE-2 and DHKF-2 $\alpha$ were highly specific: the cross-reactivities were below $0 \cdot 1 \%$ for all available prostaglandins. The intra- and interassay coefficients of variation were 10.5 and $13.0 \%$ for PGE-2, $7.0 \%$ and $9.8 \%$ for PGF- $2 \alpha, 5 \%$ and $12 \%$ for DHKE-2 and $3.9 \%$ and $15 \%$ for DHKF-2 $\alpha$, respectively.

Statistical analysis. Student's unpaired $t$ test was used to evaluate any statistical significances.

\section{Results}

Corpora lutea of pseudopregnant and pregnant rabbits contained PGE-2-9-KR in a concentration capable of converting PGE-2 into PGF-2 $\alpha$ (Table 1). Highest enzyme activities were found in both 
groups on Day 12. During pseudopregnancy elevated values of PGE-2-9-KR activity were measured on Days 10,12 and 15 while during pregnancy the increase on Day 15 did not occur. The profile of PG-15-HDH was not comparable with that of PGE-2-9-KR. The enzyme activity fluctuated between 0.1 and $0.8 \mathrm{mU} / \mathrm{mg}$ on the various days investigated without showing a stage-specific pattern or any significant elevations during pregnancy and pseudopregnancy.

The time course of PGF-2 $\alpha$ concentrations paralleled PGE-2-9-KR activity in pseudopregnancy and to a lesser extent that in pregnancy (Table 1). If luteolysis is taken in to consideration, differences in prostaglandin concentrations between the pseudopregnant and the pregnant group were surprisingly small. The concentrations of PGE-2 were generally higher than those of PGF-2 $\alpha$ except on Day 15 of pseudopregnancy, when PGF- $2 \alpha$ concentration was significantly elevated compared with pregnancy. Concentrations of the PG metabolites were lower than those of the primary prostaglandins and the DHKF- $2 \alpha$ concentrations were also lower than those of DHKE-2. No differences were measurable between corpora lutea from pseudopregnant and pregnant rabbits.

The time course and concentrations of PGE-2-9-KR, PG-15-HDH, PGE-2, PGF-2 $\alpha$ and PG metabolites were similar but generally lower in ovarian stromal tissue compared with luteal tissue. The same was true for endometrial mucosa (Table 1). In general, the activities of PGE-2-9-KR and PG-15-HDH were lower than those in the corpus luteum and no significant differences of PGE-2-9-KR activity were found in pseudopregnant and pregnant animals on Day 15. Prostaglandins and their metabolites were present in the endometrium, but revealed no significant elevations during the time of investigation.

\section{Discussion}

There is increasing evidence that prostaglandins are important factors involved in luteotrophic and luteolytic mechanisms during the life span of corpora lutea. PGE-2 is believed to act as a luteotrophic factor whereas PGF-2 $\alpha$ acts as luteolytic substance (Behrman, 1979). Two possibilities for the production of the luteolysin PGF- $2 \alpha$ are currently considered: (1) the uterus could produce this substance, as has been confirmed in several species (Heap et al., 1985; Moore et al., 1986) and (2) the ovary could itself be the site of synthesis. The rabbit seems to have no uterine control of luteal function (Keyes et al., 1983).

The present study was carried out to clarify whether the prostaglandin concentrations and the enzymic turnover of PGE-2 to PGF-2 $\alpha$ in the corpus luteum are correlated with the stage of corpus luteum function by analysing the key enzymes together with the actual prostaglandin concentrations. Our results indicate that the luteal tissue is able to metabolize and convert PGE-2 and PGF-2 $\alpha$ and that the activity of the converting enzyme, PGE-2-9-KR, is elevated at Day 15 of pseudopregnancy but not of pregnancy. The rabbit corpus luteum may therefore control its own luteolytic activity. Apart from the specific difference in PGE-2-9-KR activity, all other criteria investigated did not indicate regulatory differences between corpora lutea from pregnancy or pseudopregnancy (Table 1).

A basic output of prostaglandins was measurable in ovarian as well as in uterine tissue. Both tissues seem to have the complete enzyme pattern for producing prostaglandins and their metabolites. It therefore seems unlikely that PGF- $2 \alpha$ is transported from the uterus to the ovary. Our view is supported by findings of Lytton \& Poyser (1982) who reported low concentrations of PGE-2 in the uterine vein of rabbits during pseudopregnancy. In addition, in uterine tissue, we could not detect differences between PGE-2-9-KR activities in pseudopregnant and pregnant animals or a change in the PGF-2 $\alpha /$ PGE-2 ratio on Day 15. If a positive feedback loop mechanism does exist between the corpus luteum and uterus, it should be reflected by a higher production rate of PGF-2 $\alpha$ during Days 13-15 in the uterus of pseudopregnant animals. In contrast to the sheep (Flint \& Sheldrick, 1986), therefore, luteolysis in the rabbit may be caused by an autonomous production of PGF- $2 \alpha$ in the corpus luteum itself. 
PGF- $2 \alpha$ concentrations were found to be parallel to PGE-2-9-KR activities. These results suggest a possible participation of PGE-2-9-KR in the induction of PGF-2 $\alpha$ pulses which would shift the corpus luteum from the PGE-2-dependent to the PGF-2 $\alpha$-dependent luteolytic stage. As demonstrated by in-vitro studies, the catalytic centre of the enzyme is sensitive to physiological inhibitors (Schlegel \& Greep, 1976; Schlegel et al., 1984). These findings suggest that, in vivo, the enzyme may be regulated by naturally occurring substances.

During all days of investigation we could demonstrate relatively high concentrations of both prostaglandins (Table 1) in the corpora lutea of pregnant and pseudopregnant rabbits. The PGF$2 \alpha /$ PGE-2 ratio in general was $<0.5$ except on Day 15 of pseudopregnancy when this ratio increased to 1 . The greatest production rate of PGF- $2 \alpha$ in luteal tissues therefore seems to occur between Days 12 and 15 in pseudopregnant rabbits, although Miller et al. (1983) were not able to detect any alteration of PGF- $2 \alpha$ and PGE-2 in luteal tissue between Days 8 and 15 of pseudopregnancy in rabbits. That PGF- $2 \alpha$ may act as a luteolytic factor at a later stage in pseudopregnancy has also been suggested by McLean et al. (1987), who were unable to demonstrate any effect of PGF-2 $\alpha$ on progesterone biosynthesis in vitro at an earlier stage (Day 10) of corpus luteum function.

The catabolism of prostaglandins to metabolites by PG-15-HDH appears to have no regulatory function, although luteal tissue concentrations of DHKE-2 and DHKF-2 $\alpha$ were low compared with those of PGE-2 and PGF-2 $\alpha$ (Table 1), perhaps reflecting a steady-state situation within the cells in connection with a faster efflux of prostaglandin metabolites than their precursors. Kinetic studies in vitro have demonstrated that high concentrations of PG metabolites inhibit PG-15-HDH (Schlegel \& Greep, 1976). If this mechanism is also functional in vivo, the prostaglandin-producing systems would have to release the PG metabolites to avoid influences on the arachidonic acid cascade.

In summary, our results show that the enzymes PGE-2-9-KR and PG-15-HDH as well as PGE-2, PGF- $2 \alpha$ and their metabolites are present in the rabbit corpus luteum. A significant difference between pseudopregnant and pregnant animals was only detectable on Day 15 when PGE-2-9-KR activity as well as the PGF-2 $\alpha /$ PGE-2 ratio of pseudopregnant animals were increased. Further studies will have to focus on the intracellular regulation of PGE-2-9-KR. Antiluteolytic signals could either modulate the responsiveness of luteal cells to PGF- $2 \alpha$ or change the ratio between PGF$2 \alpha$ and PGE- 2 concentrations. Steroids could be the substances involved in these processes since they are dominant in the luteal phase in rabbits (Keyes et al., 1983) and are also involved as regulators of prostaglandin turnover (Behrman, 1979).

We thank M. Aschenbroich, R. Kusseler and D. Lehmkuhl for technical assistance. This work was supported by the special research program "Biologie und Klinik der Reproduction" of the Deutsche Forschungsgemeinschaft (Schl 140/4-5, Be 524/7-9 and partly also by Schl 140/5-1).

\section{References}

Behrman, H.R. (1979) Prostaglandins in hypothalamopituitary and ovarian function. Ann. Rev. Physiol. 41, $685-700$.

Bradford, M. (1976) A rapid and sensitive method for the quantitation of microgram quantities of protein utilizing the principle of protein-dye binding. Analyt. Biochem. 72, 248-254.

Busch, L.C., Winterhager, E. \& Fischer, B. (1986) Regeneration of the uterine epithelium in later stages of pseudopregnancy in the rabbit. An ultrastructural study. Anat. Embryol. 174, 97-104.

Fischer, B., Winterhager, E., Busch, L.C. \& Beier, H.M. (1985) Die Pseudogravidität des Kaninchens als reproduktionsbiologisches Modell. Fertilität 1, 101-109.

Fischer, B., Winterhager, E. \& Busch, L.C. (1986) Transformation of endometrium and fertility in late stages of pseudopregnancy in the rabbit. J. Reprod. Fert. 78, $529-540$.

Flint, A.P.F. \& Sheldrick, E.L. (1986) Ovarian oxytocin and the maternal recognition of pregnancy. $J$. Reprod. Fert. 76, 831-839.

Hansel, W., Concannon, P.W. \& Lukaszweska, J.A. (1973) Corpora lutea of the large domestic animals. Biol. Reprod. 8, 222-245.

Harrington, F.E. \& Rothermel, J.D. (1977) Daily changes in peripheral plasma progesterone concentrations in pregnant and pseudopregnant rabbits. Life Sci. 20, 1333-1340.

Heap, R.B., Fleet, I.R. \& Hamon, M. (1985) Prostaglandin $F-2 \alpha$ is transferred from the uterus to the ovary in the sheep by lymphatic and blood vascular pathways. $J$. Reprod. Fert. 74, 645-656. 
Horton, E.W. \& Poyser, N.L. (1976) Uterine luteolytic hormone: a physiological role for prostaglandin F-2 $\alpha$. Physiol. Rev. 56, 595-651.

Keyes, P.L., Gadsby, J.E., Yuh, K.Ch.M. \& Bill, Ch.H., III (1983) The corpus luteum. Int. Rev. Physiol. 27, 57-97.

Krüger, S. \& Schlegel, W. (1986) Prostaglandin E-2-9ketoreductase from human uterine decidua vera. Eur. J. Biochem. 157, 481-485.

Lytton, F.D.C. \& Poyser, N.L. (1982) Concentrations of PGF-2 $\alpha$ and PGE-2 in the uterine venous blood of rabbits during pseudopregnancy and pregnancy. $J$. Reprod. Fert. 64, 421-429.

McLean, M.P., Derick, R.J. \& Miller, J.B. (1987) The effect of human chorionic gonadotropin, dibutyryl cyclic adenosine $3^{\prime}, 5^{\prime}$-monophosphate, prostaglandins, and 25-hydroxycholesterol on acute progesterone secretion by dissociated rabbit luteal cells in vitro: evidence for independent effect of human chorionic gonadotropins and lipoproteins. Biol. Reprod. 36, 854-863.

Miller, J.B., Jarosik, Ch., Stanisik, D. \& Wilson, J.R.L. (1983) Alterations in plasma and tissue prostaglandin levels in rabbits during luteal regression. Biol. Reprod. 29, 824-832.

Moore, L.G., Choy, V.J., Elliot, R.L. \& Watkins, W.B. (1986) Evidence for the pulsatile release of PGF-2 $\alpha$ inducing the release of ovarian oxytocin during luteolysis in the ewe. J. Reprod. Fert. 76, 159-166.

Pong, C.Y. \& Behrman, H.R. (1981) Acute effects of prostaglandin F-2 $\alpha$ on ovarian and luteal blood flow, luteal gonadotropin uptake in vivo and gonadotropin binding in vitro. Endocrinology 108, 2239-2244.

Schlegel, W. \& Greep, R.O. (1975) Prostaglandin-15hydroxydehydrogenase from human placenta. Eur. $J$. Biochem. 56, 245-252.

Schlegel, W. \& Greep, R.O. (1976) Kinetic studies on 15hydroxyprostaglandindehydrogenase from human placenta. Adv. Prostaglandin Thromboxane Res. 1, $159-162$.

Schlegel, W., Demers, L.H., Hildebrandt-Stark, H.E., Behrman, H.R. \& Greep, R.O. (1974) Partial purification of human placental 15-hydroxyprostaglandin dehydrogenase: kinetic properties. Prostaglandins 5, 417-433.

Schlegel, W., Wenk, K., Dollinger, H.C. \& Raptis, S. (1977) Concentrations of prostaglandin A, E, F-like substances in gastric mucosa of normal subjects and of patients with various gastric diseases. Clin. Sci. molec. Med. 52, 255-258.

Schlegel, W., Urdinola, J. \& Schneider, H.P.G. (1982) Radioimmunoassay for 13,14 dihydro-15-ketoprostaglandin F-2 $\alpha$ and its application in normo- and anovulatory women. Acta endocr., Copenh. 100, 98-104.

Schlegel, W., Fischer, B., Beier, H.M. \& Schneider, H.P.G. (1983) Effects on fertilization of rabbits of insemination with ejaculates treated with PGdehydrogenases and antisera to PGE-2 and PGF- $2 \alpha$. J. Reprod. Fert. 68, 45-50.

Schlegel, W., Krüger, S. \& Korte, K. (1984) Purification of prostaglandin E-2-9-oxoreductase from human decidua vera. FEBS Lett. 171, 141-144.

Schlegel, W., Dütsch, H., Urdinola, J. \& Schneider, H.P.G. (1985) The radioimmunological estimation of 13,14-dihydro-15-keto-prostaglandin E-2 in plasma and cervical mucus. Horm. Metabol. Res. 17, 685-688.

Schlegel, W., Daniels, D. \& Krüger, S. (1987) Partial purification of prostaglandin E-2-9-ketoreductase and prostaglandin-15-hydroxydehydrogenase from ovarian tissues of rabbits. Clin. Physiol. Biochem. 5, $336-342$. 